Research Article

\title{
Control Methods for Roll Instability of Articulated Steering Vehicles
}

\author{
Xuefei Li, Jian Li, Lida Su, and Yue Cao \\ School of Mechanical Science and Engineering, Jilin University, Changchun 130022, China \\ Correspondence should be addressed to Yue Cao; caoyuejlu@163.com
}

Received 14 June 2016; Accepted 26 October 2016

Academic Editor: Francesco Braghin

Copyright (C) 2016 Xuefei Li et al. This is an open access article distributed under the Creative Commons Attribution License, which permits unrestricted use, distribution, and reproduction in any medium, provided the original work is properly cited.

\begin{abstract}
This study examines the control methods for roll instability of articulated steering vehicles (ASVs) by taking wheel loaders as the research object. An eight-degrees-of-freedom nonlinear dynamics model of ASVs was built on the basis of multibody dynamics. Three methods, namely, active braking (the front and rear axles have the same braking torque), active steering, and adjusting the swing bridge (applying a control torque between the rear body and rear axle), were adopted to analyze the effects on the roll stability of ASVs through the dynamic model. The results show that active braking is conducive to the roll stability of ASVs during turning, active steering can improve the roll stability of ASVs during turning and passing over obstacles, and adjusting the swing bridge can improve the roll stability of ASVs by changing the vehicle posture and the position of the gravity center.
\end{abstract}

\section{Introduction}

Both maneuverability and traction of off-road vehicles are important for enhanced performance in applications on unpredictable and changing terrains. To combine these two important features, articulated frame steering has become popular, and an increasing number of manufacturers choose this simple but efficient steering system. Many wheel loaders, scrapers, and forestry skidders are articulated steering vehicles (ASVs).

Modern ASVs, such as wheel loaders, are composed mainly of three parts, namely, the front body, the rear body, and the rear axle, as shown in Figure 1(a). The front body is jointed with the rear body by a steering pin. As this kind of vehicle lacks a suspension system, a swing bridge is set between the rear body and the rear axle so that each wheel will always touch the ground while driving to increase the driving force, as shown in Figure 1(b). The swing bridge is linked to the rear axle by an oscillating pin, and the upper part of the swing bridge is fixedly connected with the rear body. When the vehicle runs on uneven roads, the swing bridge guarantees that the four wheels will continuously touch the ground. While the vehicle runs on steep slopes or turns quickly, the relative rotation between the rear body and the rear axle will likely lead to the instability of the vehicle owing to the lateral force. Moreover, the lateral shift of the vehicle's gravity center during turning results in a decline in the stability of the vehicle and in a higher probability of rollover accidents [1].

To ensure the safety of the driver after the rollover, offhighway vehicles on sale are compulsorily required by the European Union and the United States to be equipped with a rollover protective structure (ROPS) that complies with international standards $[2,3]$. However, the rollover of offhighway vehicles is a dynamic impact process. In this process, the causes of casualties are varied. After the rollover, for example, the great deceleration produced when the ROPS touches the ground exceeds the impact resistance threshold of the human body. In addition, the fact that the driver repeatedly collides with the ornaments in the cab during the rollover further deteriorates the damage degree [4]. Therefore, even if the ROPS conforms to the standard requirements, casualties can still happen when the rollover occurs.

To reduce the casualties caused by the rollover of the ASVs, it is not enough to just install ROPS for passive safety protection. Research on the active safety technology of ASVs can help to solve the problem of how to avoid rollover accidents of the vehicle. Therefore, the potential rollover danger of ASVs should be monitored and assessed in real 


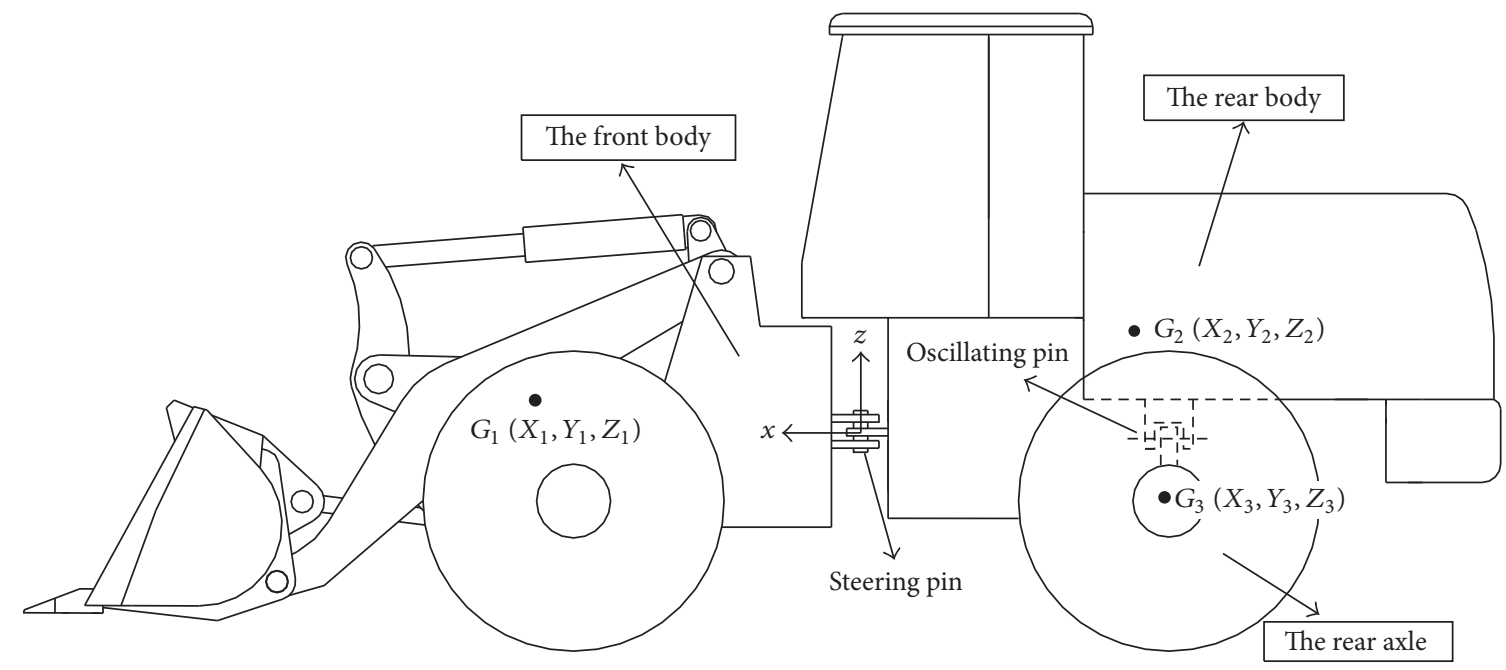

(a)

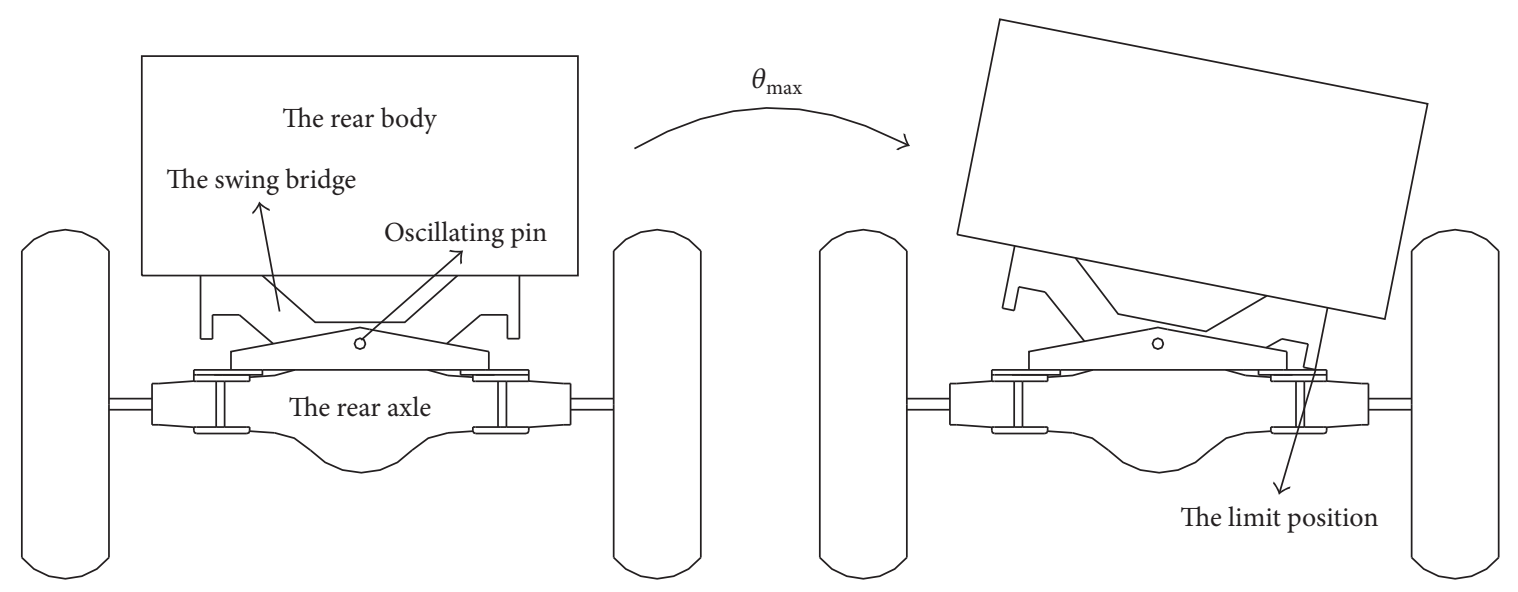

(b)

Figure 1: The structure outline of wheel loaders.

time. The stability of the vehicle should also be improved by actively adjusting the posture and the mechanical parameters. In this way, the psychological fear of the driver will also be lessened, and the driving safety of ASVs will be enhanced.

In recent years, research on the active safety technology of rollover protection has mainly targeted passenger cars on highways and heavy-duty trucks. Scholars have conducted experimental research, theoretical analysis, and computer simulation of the active safety technology of vehicles' rollover protection. Some achievements have been made in the research on the warning, precaution, and control devices of vehicle rollover. These achievements offer great reference value to the study on the active safety technology of the rollover protection of off-highway vehicles. According to relevant literature, the active control measures of vehicles' rollover protection include active steering [5-7], active braking [8, 9], active and semiactive suspension control $[10,11]$, active roll bars [12, 13], and integrated control [14-16].

According to the summary of the literature on the active rollover protection control of highway vehicles such as passenger cars and heavy-duty trucks, the stability of the vehicle can be reassured by reasonable control when instability occurs. However, ASVs and highway vehicles are very different in such aspects as work environment, body structures, rollover mechanism, and rollover actuators. Take as an example a wheel loader, which is a typical articulated steering vehicle. The device posture at work, the bucketing load, and the articulated steering angle can all change, and their changes will definitely alter the moment of inertia and lead to the position deviation of the vehicle's mass center. Moreover, ASVs usually operate on uneven roads or ramps. The geometric parameters of the ground exert great effects on the stability of the vehicles. As off-highway vehicles with work devices and articulated frames mostly operate on uneven roads, the stability theory and control methods of ASVs are all different from those of regular cars.

This study aims to establish an eight-degrees-of-freedom (DOF) nonlinear dynamic model for ASVs and to examine the control methods of active rollover protection. The established model is used to analyze the effects of active braking, active steering, and adjusting the swing bridge on the roll stability of ASVs. 


\section{The Dynamic Model of ASVs}

Typical ASVs comprise three parts, namely, the front body, the rear body, and the rear axle, as shown in Figure 1. Each part has three translational DOFs and three revolute DOFs, but all 18 DOFs are not completely independent. The longitudinal movements, lateral movements, vertical movements, and pitch movements of the front body, the rear body, and the rear axle are interrelated. The roll motions of the front body and the rear body are also connected. The yaw movements of the rear body and the rear axle are related as well. The yaw movement of the front body is linked to that of the rear body. When the vehicle starts turning, the yaw rate difference between the front body and the rear body is equal to the speed value of the steering angle. When the steering input is completed, the yaw rate of the front body is equal to that of the rear body.

According to the structure characteristics of the swing bridge, the roll motion of ASVs includes two phases.

Instability of Level 1. The swing bridge does not reach the limit position. The rear body and the rear axle roll over around the oscillating pin. Relative movements occur between the rear axle and the rear body.

Instability of Level 2. The swing bridge reaches the limit position and comes into contact with the rear axle. No further relative movements occur between the rear axle and the rear body.

Figure 2 shows the movements, the structure dimensions of the ASV, and the forces on tires. The reference point of the coordinate system of the vehicle coincides with the intersection point of the articulated steering pin axis and the oscillating pin axis, which is connected with the rear body. The $x$ axis is parallel to the chassis plane of the rear body. It points to the forward direction of the perpendicular bisector of the rear axle. The positive direction of the $z$-axis is perpendicular to the horizontal plane. The positive direction of the $y$-axis is determined by the right-hand rule. The resultant $8 \mathrm{DOF}$ are found to fully describe the movements of articulated steering vehicles: (1) the longitudinal movements of the vehicle $x$; (2) the lateral movements of the vehicle $y$; (3) the vertical movements of the vehicle $z$; 4 ) the pitch movements of the vehicle $\psi ;(5)$ the roll movements of the front body and the rear body $\theta$; (6) the roll movements of the rear axle $\theta^{\prime}$; (7) the yaw movements of the rear body and the rear axle $\varphi$; and (8) the yaw movements of the front body $\varphi^{\prime}$.

To simplify the analysis, the work device of the vehicle is assumed to be motionless; that is, the vehicle is merely being driven and is not subject to any external load other than through the tires.

According to the principle of multibody dynamics, the dynamics equations of the ASVs are written as follows.

(1) Vehicle motion along the $x$-axis direction:

$$
\begin{aligned}
& m(\ddot{x}-\dot{y} \dot{\varphi}+\dot{z} \dot{\psi}) \\
& =\sum_{i=1}^{2}\left[\left(F_{x i}+\frac{M_{T i}}{R_{t}}\right) \cos \delta-F_{y i} \sin \delta\right] \\
& \quad+\sum_{i=3}^{4}\left(F_{x i}+\frac{M_{T i}}{R_{t}}\right) .
\end{aligned}
$$

(2) Vehicle motion along the $y$-axis direction:

$$
\begin{aligned}
& m(\ddot{y}+\dot{x} \dot{\varphi}-\dot{z} \dot{\theta}) \\
& \quad=\sum_{i=1}^{2}\left[\left(F_{x i}+\frac{M_{T i}}{R_{t}}\right) \sin \delta+F_{y i} \cos \delta\right]+\sum_{i=3}^{4} F_{y i} .
\end{aligned}
$$

(3) Vehicle motion along the $z$-axis direction:

$$
m(\ddot{z}+\dot{y} \dot{\theta}-\dot{x} \dot{\psi})=\sum_{i=1}^{4} F_{z i}-\sum_{i=1}^{3} m_{i} g \cos \theta_{i} \cos \psi,
$$

where $\theta_{1}=\theta_{2}=\theta, \theta_{3}=\theta^{\prime}$.

(4) The roll motion of the front body and the rear body:

$$
\begin{aligned}
\left(J_{x x 1}\right. & \left.+J_{x x 2}\right) \ddot{\theta} \\
= & \sum_{i=1}^{2}\left[\left(F_{x i}+\frac{M_{T i}}{R_{t}}\right) \sin \delta+F_{y i} \cos \delta\right]\left(R_{t}+h\right) \\
& \quad-F_{z 1} l_{1}+F_{z 2} l_{2}-m_{1} g\left(X_{1} \sin \delta-Z_{1} \sin \theta\right) \\
& +m_{2} g Z_{2} \sin \theta+\sum_{i=1}^{2} m_{i} a_{n i} Z_{i} \cos \theta-F_{S} B_{1} .
\end{aligned}
$$

(5) The roll motion of the rear axle:

$$
\begin{aligned}
J_{x x 3} \ddot{\theta}^{\prime}= & \left(F_{y 3}+F_{y 4}\right)\left(R_{t}+h\right)+\frac{\left(F_{z 4}-F_{z 3}\right) B}{2} \\
& +m_{3} g Z_{3} \sin \theta^{\prime}+m_{3} a_{n 3} Z_{3} \cos \theta^{\prime}+F_{S} B_{2} .
\end{aligned}
$$

(6) Vehicle pitch motion around the $y$-axis:

$$
\begin{aligned}
& \left(J_{y y 1}+J_{y y 2}+J_{y y 3}\right) \ddot{\psi}=-F_{z 1} l_{3}-F_{z 2} l_{4}+\left(F_{z 3}+F_{z 4}\right) l_{r} \\
& +m_{1} g X_{1} \cos \delta+m_{2} g X_{2}-m_{3} g l_{r}+\sum_{i=1}^{3} m_{i} \ddot{x} Z_{i} \\
& +\left\{\sum_{i=1}^{2}\left[F_{y i} \sin \delta-\left(F_{x i}+\frac{M_{T i}}{R_{t}}\right) \cos \delta\right]\right. \\
& \left.-\sum_{i=3}^{4}\left(F_{x i}+\frac{M_{T i}}{R_{t}}\right)\right\}\left(R_{t}+h\right) .
\end{aligned}
$$

(7) Yaw motion of the rear body and the rear axle:

$$
\left(J_{z z 2}+J_{z z 3}\right) \ddot{\varphi}=-\left(F_{y 3}+F_{y 4}\right) l_{r}+\sum_{i=2}^{3} m_{i} a_{n i} X_{i}-M_{z}^{\prime} .
$$



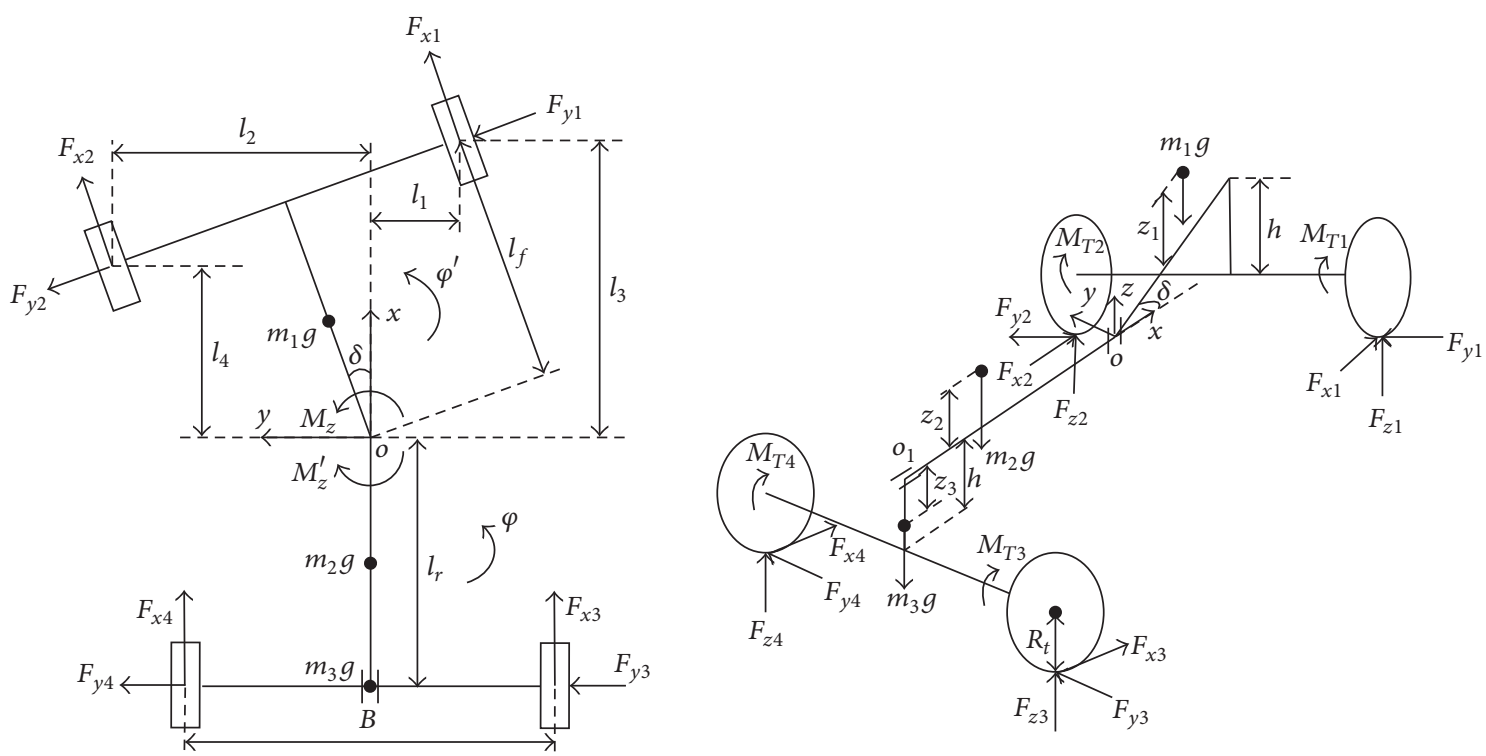

(a)
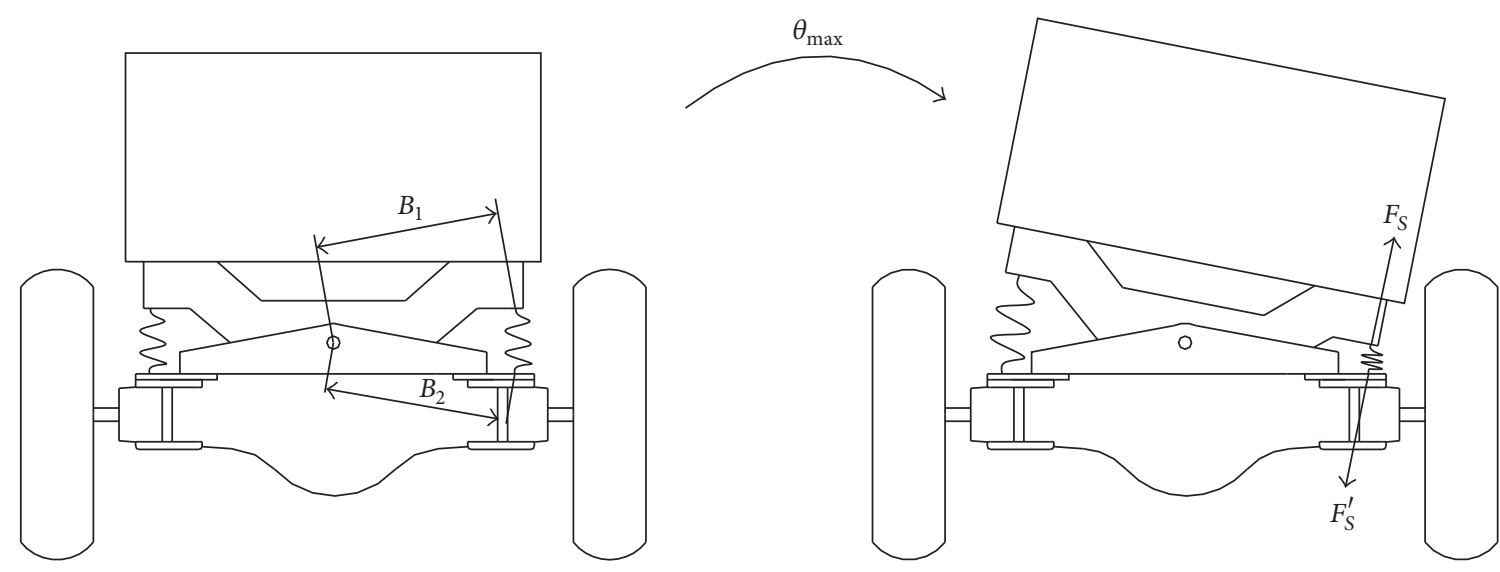

(b)

FIGURE 2: The model outline of vehicle movements.

(8) Yaw motion of the front body:

$$
J_{z z 1} \ddot{\varphi}^{\prime}=\left(F_{y 1}+F_{y 2}\right) l_{f}-m_{1} a_{n 1} X_{1}+M_{z}
$$

$$
\begin{aligned}
& a_{n 2}=\ddot{y}+\dot{x} \dot{\varphi}-\dot{z} \dot{\theta}, \\
& a_{n 3}=\ddot{y}+\dot{x} \dot{\varphi}-\dot{z} \dot{\theta}^{\prime} .
\end{aligned}
$$

where

$$
\begin{aligned}
l_{1} & =\frac{B}{2} \cos \delta-l_{f} \sin \delta, \\
l_{2} & =\frac{B}{2} \cos \delta+l_{f} \sin \delta, \\
l_{3} & =l_{F} \cos \delta+\frac{B}{2} \sin \delta, \\
l_{4} & =l_{F} \cos \delta-\frac{B}{2} \sin \delta, \\
a_{n 1} & =\ddot{x}+\dot{x} \dot{\varphi}^{\prime}-\dot{z} \dot{\theta},
\end{aligned}
$$

$F_{S}$ is the contact force which is generated when the swing bridge reaches the limit position. In order to calculate $F_{S}$, the contact process is assumed to be connected by a spring and damping system, as shown in Figure 2(b), and $F_{S}$ can be written as follows:

$$
F_{S}=K_{S}\left(B_{1} \theta-B_{2} \theta^{\prime}\right)+C_{S}\left(B_{1} \dot{\theta}-B_{2} \dot{\theta}^{\prime}\right)
$$

where $K_{S}$ is contact stiffness and $C_{S}$ is contact damping. $K_{S}=$ 0 and $C_{S}=0$ when the swing bridge does not reach the limit position. $B_{2}$ is the distance between the oscillating pin and the limit position, $B_{1} \approx B_{2}$. 
Note that the above equations focus on the motion of the vehicle without the wheels, and the equations of the motion of the wheels will be later added in Section 3 .

\section{The Tire Model}

In this paper, the Fiala Tire Model is adopted to calculate the longitudinal force, the vertical force, and the lateral force of the tires [17].

(1) Side-Slip Angle. Lateral wheel slip is defined as (11). The side-slip angles of the tires in our model can be calculated using (12). Consider

$$
\begin{aligned}
\tan \alpha_{i} & =-\frac{v_{y_{i}}}{v_{x i}}, \\
\alpha_{1} & =-\arctan \frac{\dot{y} \cos \delta-\dot{x} \sin \delta+l_{f} \dot{\varphi}^{\prime}}{\dot{x} \cos \delta+B \dot{\varphi}^{\prime} / 2}, \\
\alpha_{2} & =-\arctan \frac{\dot{y} \cos \delta-\dot{x} \sin \delta+l_{f} \dot{\varphi}^{\prime}}{\dot{x} \cos \delta-B \dot{\varphi}^{\prime} / 2}, \\
\alpha_{3} & =-\arctan \frac{\dot{y}-l_{r} \dot{\varphi}}{\dot{x}+B \dot{\varphi} / 2} \\
\alpha_{4} & =-\arctan \frac{\dot{y}-l_{r} \dot{\varphi}}{\dot{x}-B \dot{\varphi} / 2} .
\end{aligned}
$$

(2) Normal Force.

$$
F_{z i}=-\left[K_{v i}\left(d_{i}-s_{i}\right)+C_{v i}\left(\dot{d}_{i}-\dot{s}_{i}\right)\right] .
$$

$d_{i}$ is each displacement of the four tires in the $z$ direction of the global coordinate system, which can be calculated as follows:

$$
\begin{aligned}
& d_{1}=z-l_{1} \theta-l_{3} \psi, \\
& d_{2}=z+l_{2} \theta-l_{4} \psi, \\
& d_{3}=z+l_{r} \psi-\frac{B}{2} \theta^{\prime}, \\
& d_{4}=z+l_{r} \psi+\frac{B}{2} \theta^{\prime} .
\end{aligned}
$$

$s_{i}$ is the vertical displacement of the $i$ th tire caused by obstacles.

The ASVs may pass over various shapes of obstacles in actual conditions, but we can not consider every obstacle in the theoretical analysis. In order to facilitate the establishment of a mathematical model of obstacles, regularly shaped obstacles have been chosen, such as triangular, circular, and square-shaped obstacles.

Figure 3 shows the wheel loader that passes over a triangular obstacle. As the vehicle symmetry, this paper only analyzes roll stability of the ASVs when the left wheels pass over obstacles. $s_{i}$ can be written as follows:

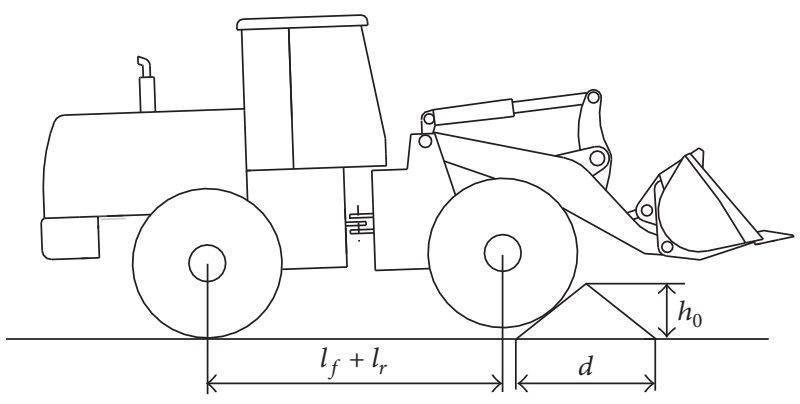

Figure 3: The sketch of the ASV that passes over obstacle.

The right front wheel: $s_{1}=0$.

The left front wheel:

$$
s_{2}= \begin{cases}0 & \left(0 \leq t<t_{0}\right) \\ k\left(t-t_{0}\right) & \left(t_{0} \leq t<t_{0}+t_{d 1}\right) \\ -k\left(t-t_{0}-t_{d 1}\right)+h_{0} & \left(t_{0}+t_{d 1} \leq t<t_{0}+t_{d}\right) \\ 0 & \left(t \geq t_{0}+t_{d}\right) .\end{cases}
$$

The right rear wheel: $s_{3}=0$.

The left rear wheel:

$$
\begin{aligned}
& s_{4} \\
& = \begin{cases}0 & \left(0 \leq t<t_{0}+t_{l}\right) \\
k\left(t-t_{0}-t_{l}\right) & \left(t_{0}+t_{l} \leq t<t_{0}+t_{l}+t_{d 1}\right) \\
-k\left(t-t_{0}-t_{l}-t_{d 1}\right)+h_{0} & \left(t_{0}+t_{l}+t_{d 1} \leq t<t_{0}+t_{l}+t_{d}\right) \\
0 & \left(t \geq t_{0}+t_{l}+t_{d}\right),\end{cases}
\end{aligned}
$$

where $k=2 h_{0} / d, t_{d 1}=d / 2 v, t_{d}=d / v$, and $t_{l}=\left(l_{r}+l_{f}\right) / v$.

In the solution process, $d_{i}-s_{i}>0$ indicates that the $i$ th wheel lifts off from the ground; set $K_{v i}=0, C_{v i}=0$, and $K_{\alpha i}=0$.

\section{(3) Longitudinal Force.}

$$
F_{x}= \begin{cases}K_{x} \lambda, & |\lambda| \leq \lambda_{\text {critical }} \\ -\operatorname{sign}(\lambda)\left(F_{x 1}-F_{x 2}\right), & |\lambda|>\lambda_{\text {critical }},\end{cases}
$$

where $\lambda_{\text {critical }}$ is the critical longitudinal slip which is used to determine whether tires are sliding or not.

$$
\lambda_{\text {critical }}=\left|\frac{\mu F_{z}}{2 K_{x}}\right| .
$$

The friction coefficient, which depends on static friction $\left(\mu_{s}\right)$, sliding friction $\left(\mu_{d}\right)$, longitudinal slip ratio $(\lambda)$, and sideslip angle $(\alpha)$, is defined as

$$
\mu=\mu_{s}-\left(\mu_{s}-\mu_{d}\right) \sqrt{\lambda^{2}+\tan ^{2} \alpha} .
$$


$F_{x 1}$ and $F_{x 2}$ can be calculated as follows:

$$
\begin{aligned}
& F_{x 1}=\mu\left|F_{z}\right|, \\
& F_{x 2}=\left|\frac{\left(\mu F_{z}\right)^{2}}{\left(4 \lambda K_{x}\right)}\right| .
\end{aligned}
$$

$\lambda$, the longitudinal slip ratio, is calculated as follows:

$$
\lambda_{i}= \begin{cases}\frac{R_{i} \omega_{i}-v_{x i}}{R_{i} \omega_{i}} & \text { (acceleration: } \left.R_{i} \omega_{i} \geq v_{x i}\right) \\ \frac{R_{i} \omega_{i}-v_{x i}}{v_{x i}} & \text { (braking: } \left.R_{i} \omega_{i}<v_{x i}\right) .\end{cases}
$$

The dynamics of each individual wheel are given by

$$
\dot{\omega}_{i}=\frac{M_{T i}-R_{i} F_{x i}}{I_{w}} \quad(i=1,2,3,4),
$$

where $M_{T i}$ is driving/braking torque and $I_{w}$ is rotational inertia of wheel.

This paper focuses on the effects of active braking on roll instability of ASVs. The time derivative of the $i$ th wheel longitudinal slip in braking process is given by

$$
\dot{\lambda}_{i}=\frac{R_{i} \dot{\omega}_{i}}{v_{x i}}-\left(1+\lambda_{i}\right) \frac{\dot{v}_{x i}}{v_{x i}} .
$$

Substituting from (22) into (23) gives

$$
\dot{\lambda}_{i}=-\frac{R_{i}^{2}}{I_{w} v_{x i}} F_{x i}-\left(1+\lambda_{i}\right) \frac{\dot{v}_{x i}}{v_{x i}}-\frac{R_{i}}{I_{w} v_{x i}} M_{T i} .
$$

(4) Lateral Force.

$$
F_{y}= \begin{cases}-\mu\left|F_{z}\right|\left(1-H^{3}\right) \operatorname{sign}(\alpha), & |\alpha| \leq \alpha_{\text {critical }} \\ -\mu\left|F_{z}\right| \operatorname{sign}(\alpha), & |\alpha|>\alpha_{\text {critical }},\end{cases}
$$

where $\alpha_{\text {critical }}$ is critical lateral slip, which is used to judge whether tires are sliding or not, $\alpha_{\text {critical }}=\arctan \left(3 \mu F_{z} / K_{\alpha}\right)$, and $H=1-\left(K_{\alpha}|\tan \alpha|\right) /\left(3 \mu\left|F_{z}\right|\right)$.

\section{Research on the Control Methods of Roll Instability of ASVs}

The above dynamic model of ASVs has been verified with experiments, which can be seen in [18]. The experiment results achieved high conformity with the simulation ones. The established dynamic model could reasonably describe the movements of ASVs.

This section will respectively control such parameters as the braking torque, the articulated steering angle, and the oscillating angle when instability occurs. The inhibition effects of the above parameters on the instability of ASVs will be analyzed. In this article, the ZL50 wheel loader is selected as the research object. Its main parameters are shown in Table 1. The inputs of the steering angle are shown in Figure 4. The parameters of static friction $\mu_{s}$ and sliding friction $\mu_{d}$ are set as 0.6 and 0.4 , respectively.

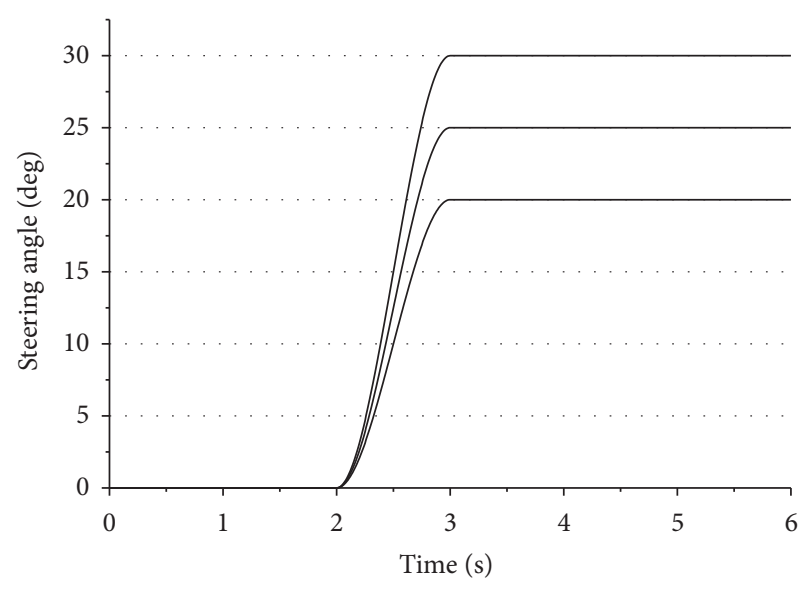

FIGURE 4: The inputs of the steering angle.

Here we choose the lateral load transfer ratio (LTR) as stability index to indicate the vehicle rollover propensity, which is defined as

$$
\operatorname{LTR}=\left|\frac{F_{z R}-F_{z L}}{F_{z R}+F_{z L}}\right|=\left|\frac{\left(F_{z 1}+F_{z 3}\right)-\left(F_{z 2}+F_{z 4}\right)}{F_{z 1}+F_{z 3}+F_{z 2}+F_{z 4}}\right| .
$$

The LTR varies from 0 to 1 , where 0 refers to equal vertical forces on both sides of the vehicle (zero roll) and 1 refers to either the left or right vehicle tires losing contact with the ground.

4.1. Effects of Active Braking on the Roll Instability of ASVs. Whether the difference between the roll angle of the rear body $\theta$ and the roll angle of the rear axle $\theta^{\prime}$ reaches the maximum roll angle $\theta_{\max }$ decides whether the instability of Level 2 has taken place. When the vehicle normally progresses forward, no braking torque is input in the process. When the instability of Level 2 occurs, the input of the driving torque is changed to that of the braking torque. The vehicle begins to slow down. The braking time is adjusted by regulating the amount of braking torque. Note that the front and rear axles have the same braking torque in this study.

4.1.1. Effects of Active Braking on the Rollover Stability during Steering. The following two working conditions are set: (1) the steering angle is $20^{\circ}$ and the corresponding forward speed is $8 \mathrm{~m} / \mathrm{s}$. (2) The steering angle is $25^{\circ}$ and the corresponding forward speed is $7 \mathrm{~m} / \mathrm{s}$. The input curve of the steering angle is shown in Figure 4. When instability occurs, the braking torque is imposed and adjusted, so that the braking time of the vehicle will be $3 \mathrm{~s}$. Figure 5 shows the comparison of the motion states of the vehicle between two kinds of circumstances, with braking and without braking, when steering instability occurs. When the vehicle proceeds in the above two working conditions, instability occurs after turning if active braking is not wielded. After active braking, the vehicle can recover the steady state from the unstable state. Therefore, when steering instability occurs, the measure of active braking can improve the roll stability of ASVs. The instability of the vehicle during steering is largely due to the great lateral 
TABLE 1: Parameters of the scaled ASV and the ZL50 wheel loader.

\begin{tabular}{|c|c|c|}
\hline Parameters & Meanings and units & Value \\
\hline$m$ & Total mass of ASV (kg) & 16747.4 \\
\hline$m_{1}$ & Front body mass (kg) & 6979.8 \\
\hline$m_{2}$ & Rear body mass (kg) & 8896.0 \\
\hline$m_{3}$ & Rear axle mass (kg) & 871.6 \\
\hline$J_{x x 1} / J_{y y 1} / J_{z z 1}$ & Moment of inertia of front body $\left(\mathrm{kg} \cdot \mathrm{m}^{2}\right)$ & $5248 / 32310 / 32977$ \\
\hline$J_{x x 2} / J_{y y 2} / J_{z z 2}$ & Moment of inertia of rear body $\left(\mathrm{kg} \cdot \mathrm{m}^{2}\right)$ & $5842 / 14982 / 13228$ \\
\hline$J_{x x 3} / J_{y y 3} / J_{z z 3}$ & Moment of inertia of rear axle $\left(\mathrm{kg} \cdot \mathrm{m}^{2}\right)$ & $1428 / 1238 / 1431.0$ \\
\hline$W_{1}\left(X_{1}, Y_{1}, Z_{1}\right)$ & CG of front body (m) & $(1.80,0.03,0)$ \\
\hline$W_{2}\left(X_{2}, Y_{2}, Z_{2}\right)$ & CG of rear body $(\mathrm{m})$ & $(-1.86,0.06,0.61)$ \\
\hline$W_{3}\left(X_{3}, Y_{3}, Z_{3}\right)$ & CG of rear axle $(\mathrm{m})$ & $(-1.67,0,-0.41)$ \\
\hline$B$ & Tread (m) & 2.30 \\
\hline$B_{2}$ & Distance between the oscillating pin and the limit position (m) & 0.47 \\
\hline$l_{f}$ & Distance between the steering pin and the front axle $(\mathrm{m})$ & 1.55 \\
\hline$l_{r}$ & Distance between the steering pin and the rear axle (m) & 1.67 \\
\hline$R_{t}$ & Tire radius $(\mathrm{m})$ & 0.87 \\
\hline$h$ & Distance between the oscillating pin and the rear axle (m) & 0.32 \\
\hline$K_{x}$ & Longitudinal stiffness of tire $(\mathrm{N} / \mathrm{m})$ & $9.7 \times 10^{6}$ \\
\hline$K_{\alpha}$ & Cornering stiffness of tire (N/deg) & $4.8 \times 10^{6}$ \\
\hline$K_{v}$ & Vertical stiffness of tire $(\mathrm{N} / \mathrm{m})$ & $2.9 \times 10^{6}$ \\
\hline$C_{v}$ & Vertical damping of tire $(\mathrm{N} \cdot \mathrm{s} / \mathrm{m})$ & $4.27 \times 10^{5}$ \\
\hline$I_{w}$ & Moment of inertia of wheel $\left(\mathrm{kg} \cdot \mathrm{m}^{2}\right)$ & 117.4 \\
\hline$K_{S}$ & Contact stiffness $(\mathrm{N} / \mathrm{m})$ & $1 \times 10^{8}$ \\
\hline$C_{S}$ & Contact damping $(\mathrm{N} \cdot \mathrm{s} / \mathrm{m})$ & $1 \times 10^{4}$ \\
\hline$\theta_{\max }$ & Maximum angle of swing bridge (deg) & 15 \\
\hline
\end{tabular}

acceleration. The forward speed of the vehicle decreases rapidly in the process of braking and so does the lateral acceleration. Then, the vehicle will regain stability.

\subsubsection{Effects of Active Braking on the Rollover Stability While} Passing over Obstacles. The obstacle is in the shape of an isosceles triangle. Two working conditions are set by the size of the obstacle and the forward speed of the vehicle: (a) the base and the height of the triangle are $0.8 \mathrm{~m}$ and $0.3 \mathrm{~m}$, respectively. The forward speed of the vehicle is $7 \mathrm{~m} / \mathrm{s}$. (b) The base and the height of the triangle are $0.8 \mathrm{~m}$ and $0.4 \mathrm{~m}$, respectively. The forward speed of the vehicle is $6 \mathrm{~m} / \mathrm{s}$.

When instability occurs in the process of obstacle crossing, active braking is applied so that the braking time will be $2 \mathrm{~s}$ and $3 \mathrm{~s}$, respectively. Figure 6 shows the comparison of the vehicle's motion states between two kinds of circumstances, with braking and without braking, when the vehicle passes over different obstacles and instability occurs. The figure shows that the time when the lateral load transfer rate (LTR) reaches 1 does not change after braking. The trend of the roll angle speed does not change either. As a result, the following conclusions can be drawn:

(1) If instability occurs when the vehicle passes over the obstacles straight, braking cannot help the vehicle recover the stable state.

(2) Instability occurs during obstacle crossing mostly because of a sudden change in the vertical force of the tires, thus making the roll angle velocity accelerate quickly in a short period of time. Once the roll angle velocity surpasses the threshold, instability occurs and braking cannot change the vertical movement of the vehicle.

\subsection{Effects of Active Steering on the Roll Stability of ASVs}

4.2.1. Effects of Active Steering on the Roll Stability When Steering Instability Occurs. Two working conditions are set: (a) the steering angle is $20^{\circ}$ and the corresponding forward speed is $8 \mathrm{~m} / \mathrm{s}$. (b) The steering angle is $25^{\circ}$ and the corresponding forward speed is $7 \mathrm{~m} / \mathrm{s}$. When instability occurs in the process of turning, it will only worsen the rollover of the vehicle to continue to steer in the same direction. Therefore, nothing can be analyzed here but the situation in which the vehicle turns in the opposite direction when steering instability occurs. The effects on stability in this situation are revealed in Figure 7 . Based on the change in LTR, active steering can effectively restrain the instability of the vehicle. Steering instability is mainly caused by the great lateral acceleration. When steering instability occurs, active steering in the opposite direction can enlarge the turning radius and diminish the lateral acceleration.

4.2.2. Effects of Active Steering on the Roll Stability While Passing over an Obstacle. The obstacle crossing discussed in this study is based on the assumption that the left-side 

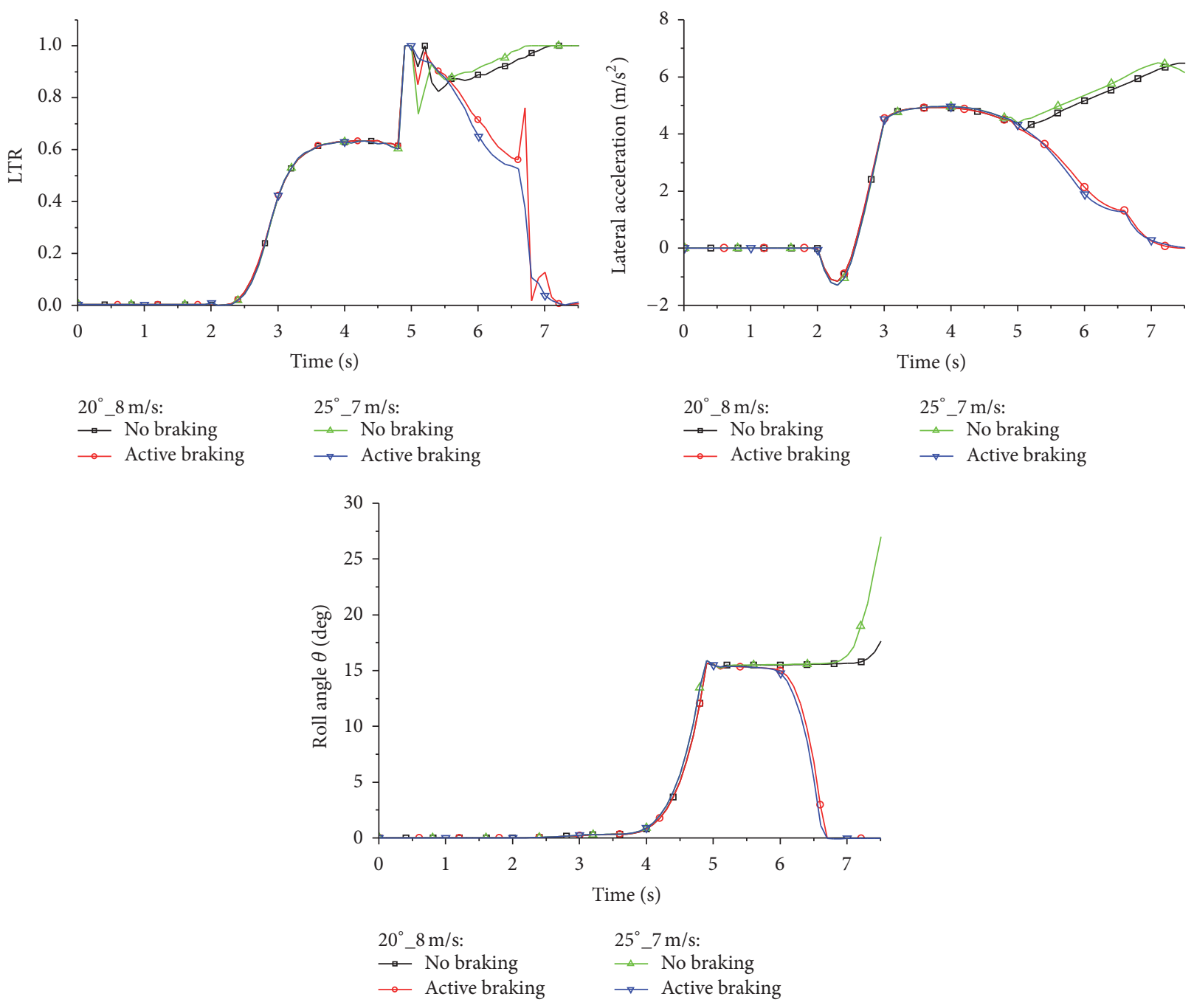

FIGURE 5: The comparison of the vehicle's motion states before and after active braking when steering instability occurs.

wheels pass over obstacles in the advancing direction. When instability occurs, the vehicle rolls over around the positive direction of the $x$-axis. To analyze the effects of active steering on the roll stability while passing over an obstacle, two conditions are set: (a) the base and the height of the triangle obstacle are $0.8 \mathrm{~m}$ and $0.3 \mathrm{~m}$, respectively. The forward speed of the vehicle is $7 \mathrm{~m} / \mathrm{s}$. (b) The base and the height of the triangle obstacle are $0.8 \mathrm{~m}$ and $0.4 \mathrm{~m}$, respectively. The forward speed of the vehicle is $6 \mathrm{~m} / \mathrm{s}$. When instability occurs, active steering on the left and the right are both applied (at the steering angle of $20^{\circ}$ in $1 \mathrm{~s}$ of the steering time). The analysis results are shown in Figure 8. The results of two kinds of working conditions show that active steering can change the variation tendency of stability when instability occurs during obstacle crossing. The specific results are as follows:

(1) When the vehicle rolls over around the positive direction of the $x$-axis (the right-side rollover in the advancing direction), turning right worsens the rollover of the vehicle. As shown in Figure 8, the vehicle can regain stability after about $3 \mathrm{~s}$ without active steering on the right. However, the vehicle will roll over instantly if active steering on the right is wielded.

(2) When the vehicle rolls over around the positive direction of the $x$-axis, turning left can curb the instability of the vehicle. After active steering on the left, the instability time of the vehicle can be shortened to $1.5 \mathrm{~s}$ from the original $3 \mathrm{~s}$. Active steering on the left is assumed to help the vehicle to quickly recover the stable state from the unstable state.

For positive rollover scenario around $x$-axis, active steering on the left can improve the roll stability of the vehicle, but active steering on the right can deteriorate the instability of the vehicle. The main reason for this phenomenon is that the CG of the vehicle will shift laterally while steering. When the vehicle rolls over around the positive direction of the $x$ axis, turning left makes the CG of the vehicle shift to the left, which can curb the instability of the vehicle. On the contrary, turning right causes the CG of the vehicle to shift to the right, which accelerates vehicle instability. 

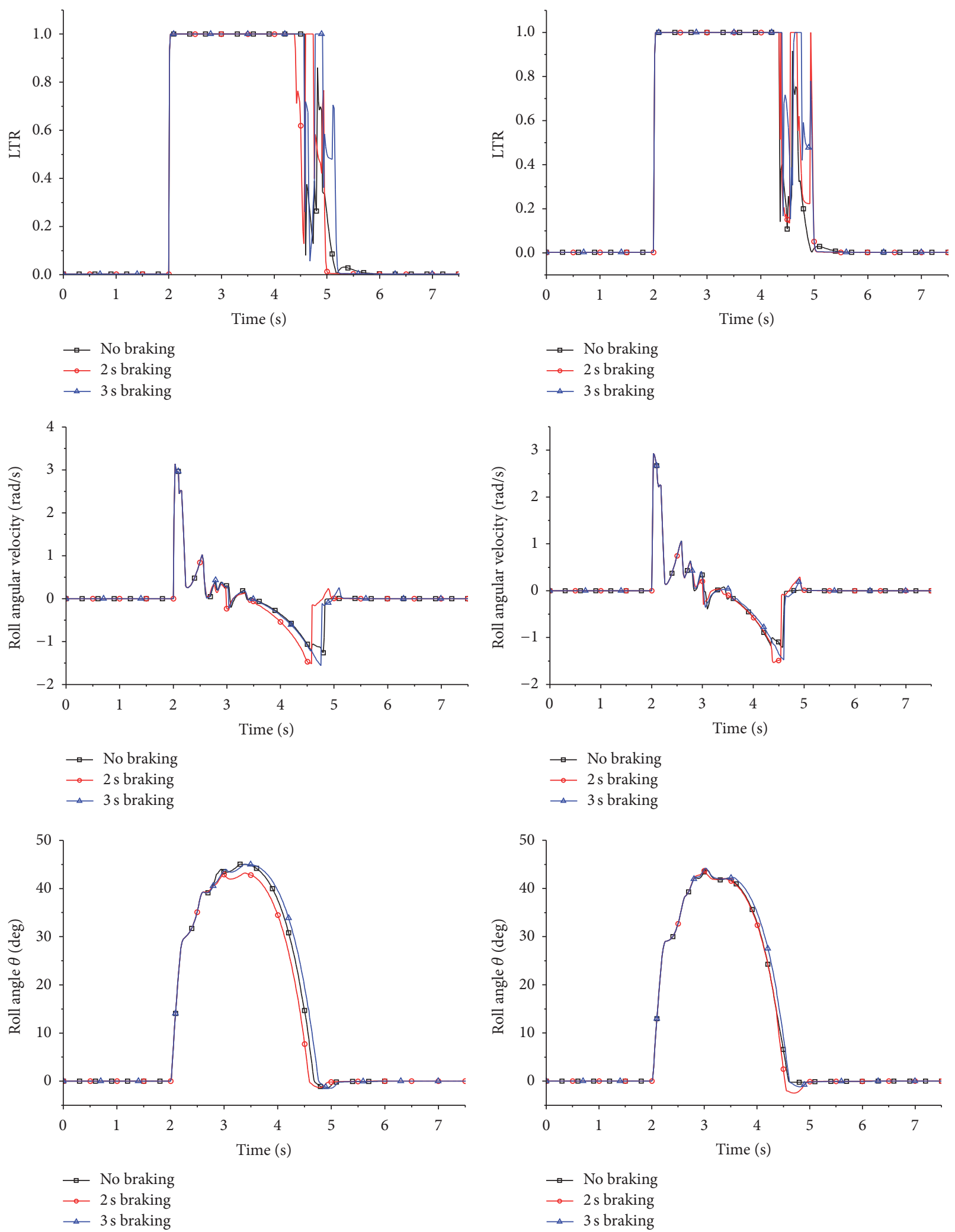

(a)

(b)

FIGURE 6: The comparison of the vehicle's motion states before and after active braking if instability occurs when the vehicle is crossing the obstacles straight. 

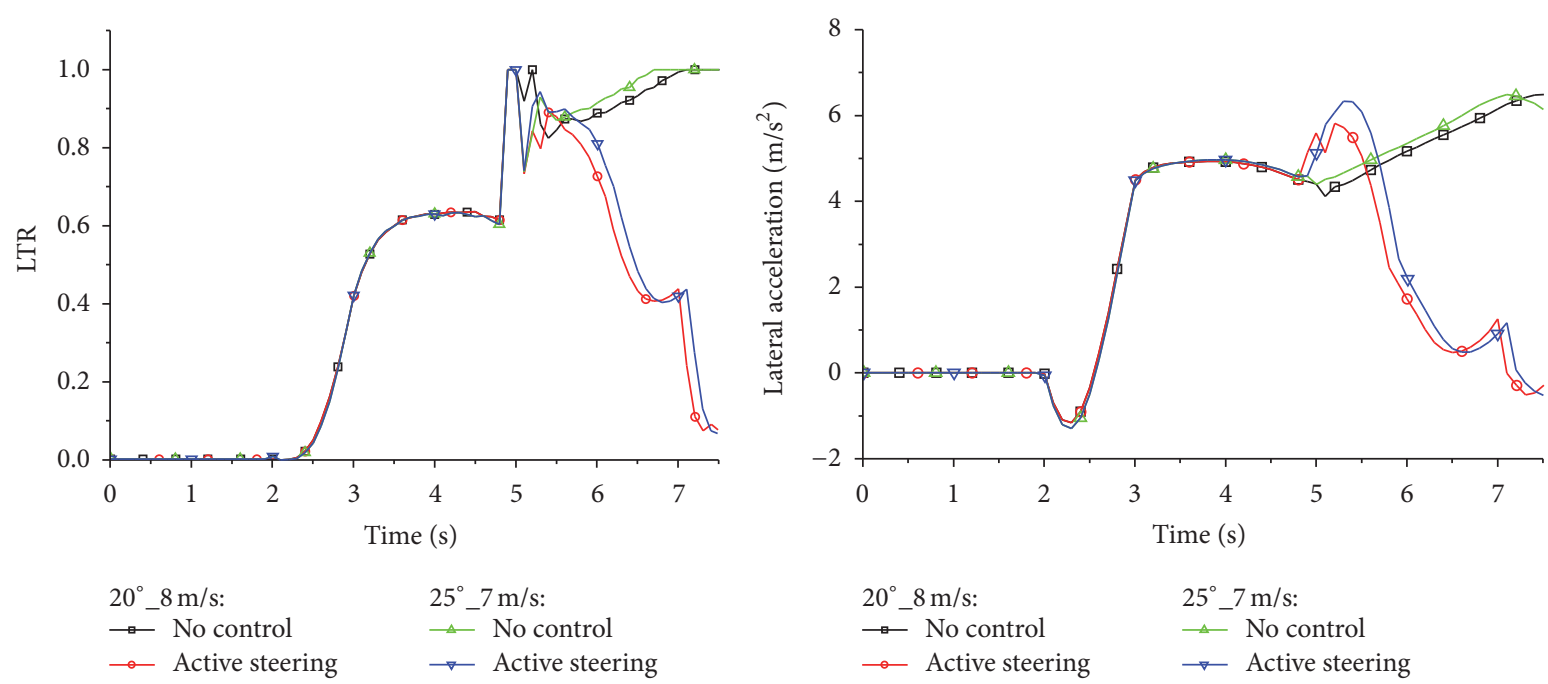

$$
\begin{array}{ll}
20^{\circ} \_8 \mathrm{~m} / \mathrm{s}: & 25^{\circ} \_7 \mathrm{~m} / \mathrm{s}: \\
\rightarrow \text { No control } & \longleftarrow \text { No control } \\
\rightarrow \text { Active steering } & \square \text { Active steering }
\end{array}
$$

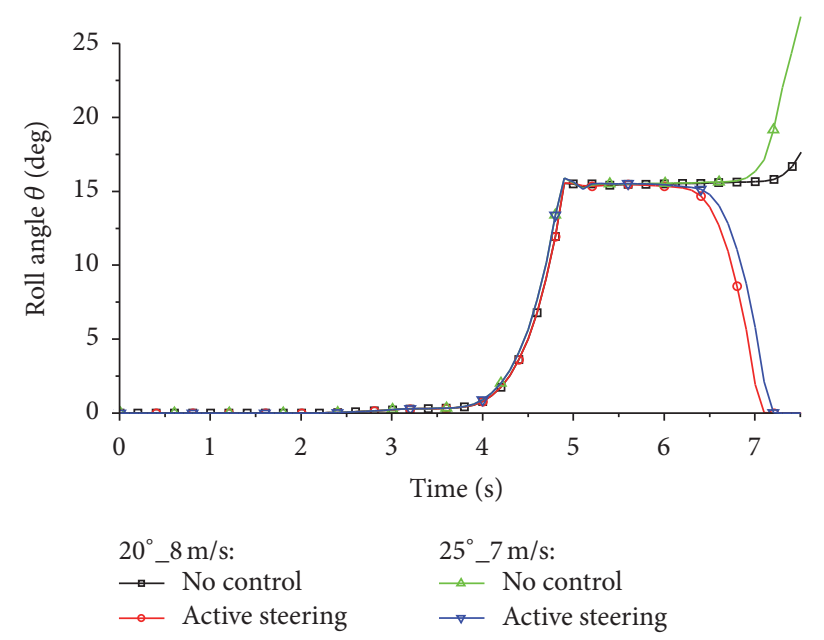

FIGURE 7: The effects of active steering on the vehicle stability when instability occurs in a quick turning.

4.3. Effects of Adjusting the Swing Bridge on the Roll Stability of $A S V$ s. Figure 9(a) shows the entire roll process of articulated steering vehicles. With the supposition that the swing bridge can be adjusted by applying a control torque between the rear axle and the rear body in the roll process, the swing bridge is set on the left of the limit position, as shown in Figure 9(b). When the swing bridge is adjusted, the gravity center of the vehicle shifts to the left. This shift may decrease the rollover trend of the vehicle or even prevent the vehicle from rolling over.

If the swing bridge is intended to rotate reversely around the pin and to implement the adjustment shown in Figure 9(b), the restoring torque $M_{B}$ needs to be imposed on the swing bridge when instability takes place in ASVs. The dynamic model established in the second session also needs corresponding improvements. The driving torque imposed on the swing bridge only influences the roll motion of the vehicle. The remaining dynamic equations of the motion remain the same. The dynamic equations of the roll motion of the front body, the back body, and the rear axle are the ones that only need to be modified.
The Roll Motion of the Front Body and the Rear Body.

$$
\begin{aligned}
\left(J_{x x 1}\right. & \left.+J_{x x 2}\right) \ddot{\theta} \\
= & \sum_{i=1}^{2}\left[\left(F_{x i}+\frac{M_{T i}}{R_{t}}\right) \sin \delta+F_{y i} \cos \delta\right]\left(R_{t}+h\right) \\
& -F_{z 1} l_{1}+F_{z 2} l_{2}-m_{1} g\left(X_{1} \sin \delta-Z_{1} \sin \theta\right) \\
& +m_{2} g Z_{2} \sin \theta+\sum_{i=1}^{2} m_{i} a_{n i} Z_{i} \cos \theta-F_{S} B_{1}-M_{B} .
\end{aligned}
$$

The Roll Motion of the Rear Axle.

$$
\begin{aligned}
J_{x x 3} \ddot{\theta}^{\prime}= & \left(F_{y 3}+F_{y 4}\right)\left(R_{t}+h\right)+\frac{\left(F_{z 4}-F_{z 3}\right) B}{2} \\
& +m_{3} g Z_{3} \sin \theta^{\prime}+m_{3} a_{n 3} Z_{3} \cos \theta^{\prime}+F_{S}^{\prime} B_{2} \\
& +M_{B} .
\end{aligned}
$$

The roll angle velocity and the lateral acceleration vary in the roll process of the vehicle. As a result, the rotating 

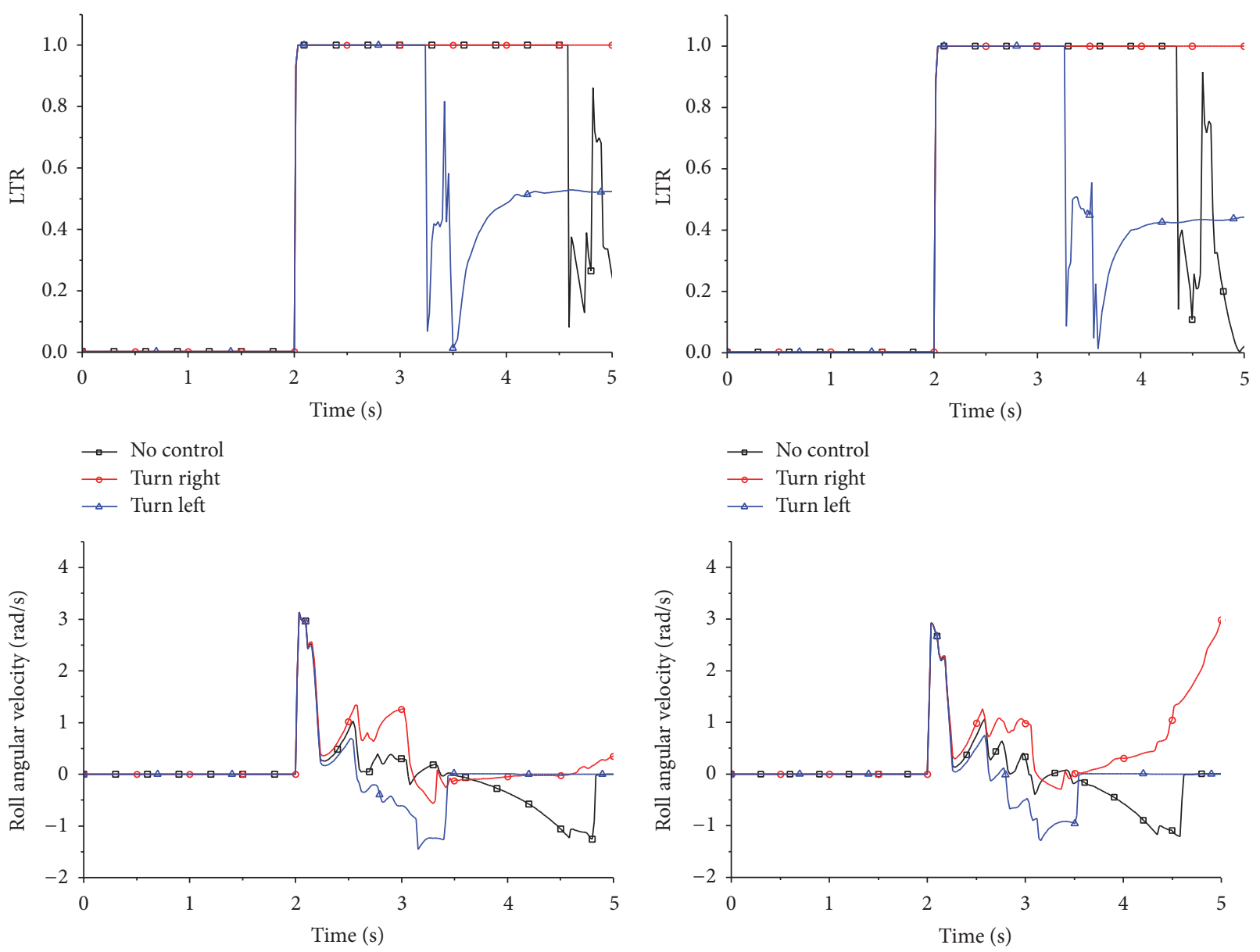

$$
\begin{aligned}
& \rightarrow \text { No control } \\
& \rightarrow \text { Turn right } \\
& \triangle \quad \text { Turn left }
\end{aligned}
$$

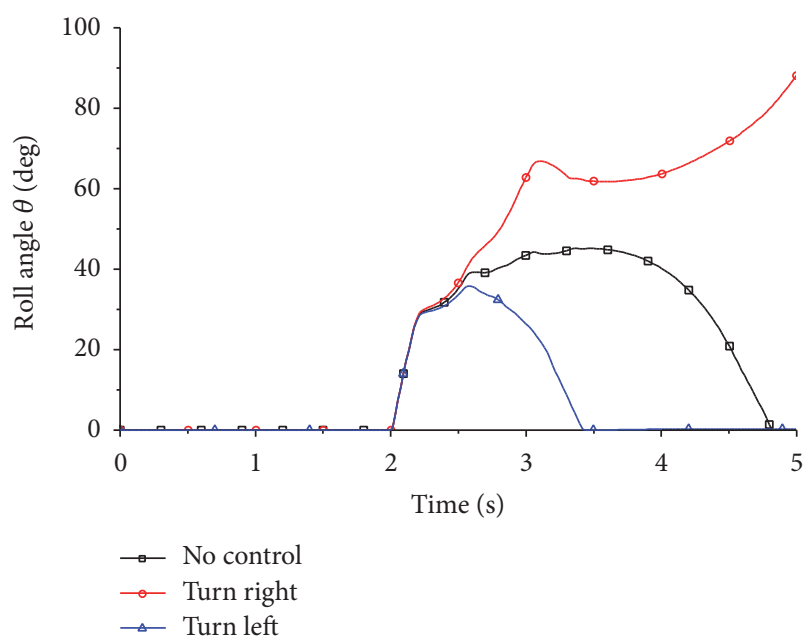

(a)

$\rightarrow$ No control

$\rightarrow$ Turn right

$\triangle$ Turn left

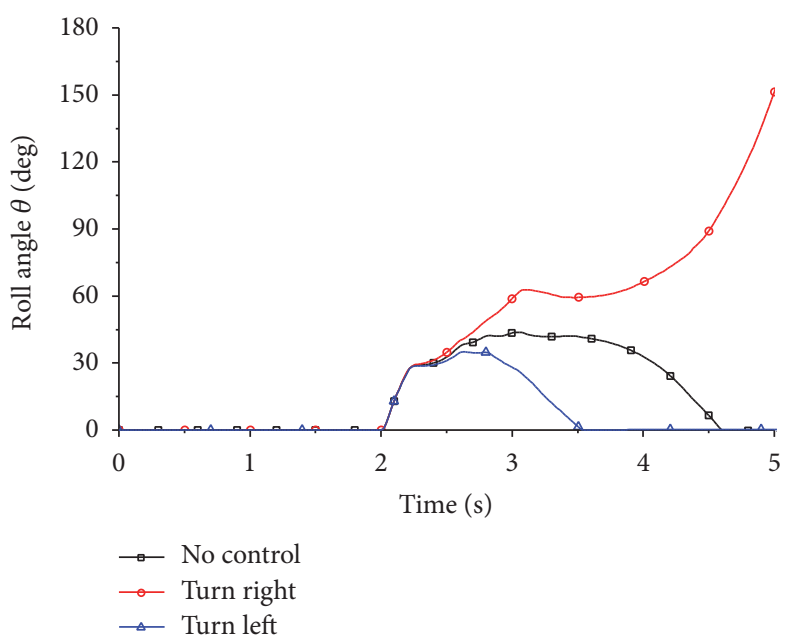

(b)

FIGURE 8: The effects of active steering on the vehicle stability if instability occurs when the vehicle is passing over the obstacles straight. 


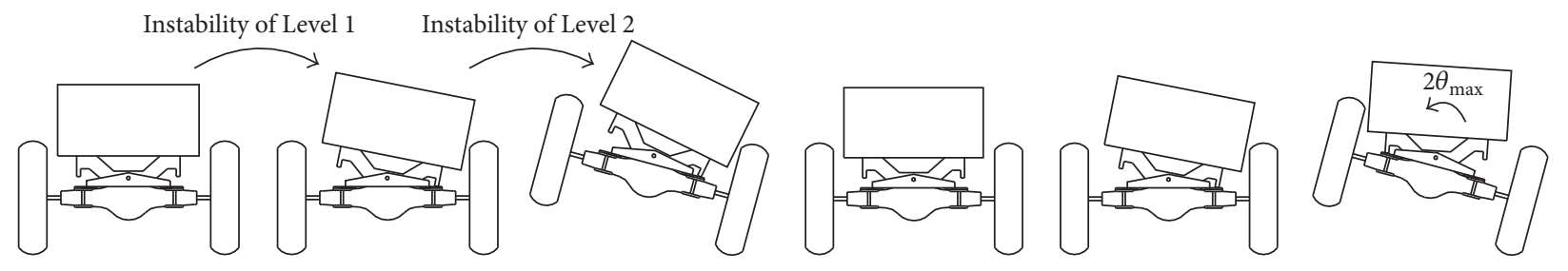

(a)

(b)

FIGURE 9: The instability process of the vehicle with and without controlling the swing bridge.

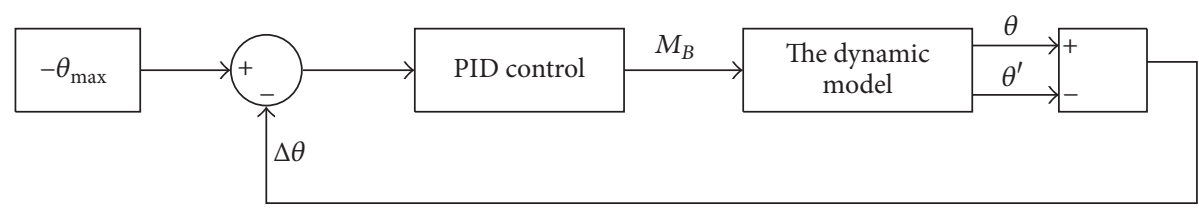

FIGURE 10: Block diagram of the rotating torque control.

torque $M_{B}$ required to make the swing bridge return to the center varies accordingly. Calculating the precise value of the rotating torque $M_{B}$ is slightly difficult. However, this section only focuses on whether or not the aligning of the swing bridge can improve the roll stability of the vehicle. Therefore, the precise value of the rotating torque $M_{B}$ is not emphasized in the calculation process. Here $M_{B}$ is adjusted by the PID. Figure 10 is the block diagram of the control. After the rollover of the vehicle is confirmed $\left(\theta-\theta^{\prime} \geq \theta_{\max }\right)$, the swing bridge can rotate $2 \theta_{\text {max }}$ in the opposite direction of the roll by adjusting the PID parameters in theory. In the process of model calculation, the swing bridge stops rotating immediately as long as the left front wheel touches the ground. The swing bridge returns to the center thanks to the tire force. At this point, the value of the rotating torque remains constant.

Whether the difference between the roll angle of the back body $\theta$ and the roll angle of the rear axle $\theta^{\prime}$ reaches the maximum roll angle $\theta_{\max }$ decides whether the instability of Level 2 has occurred. If the instability of Level 2 does not happen, the input of the rotating torque $M_{B}$ will be 0 . The swing bridge can oscillate freely without being controlled. If the instability of Level 2 occurs, the input of the rotating torque $M_{B}$ will no longer be 0 . The control principle is shown in Figure 10. Under the action of $M_{B}$, the swing bridge keeps rotating reversely until the left front wheel touches the ground.

4.3.1. Effects of Adjusting the Swing Bridge on the Roll Stability When Steering Instability Occurs. When the vehicle runs on horizontal surfaces, the input of the steering angle is $30^{\circ}$ within $1 \mathrm{~s}$, and the forward speed is $6.5 \mathrm{~m} / \mathrm{s}$. Figure 11(a) shows the motion states of the vehicle with and without adjusting the swing bridge. In the process of a quick turn, the LTR value ultimately reaches 1 , and instability will occur if the swing bridge is not adjusted. If the swing bridge is adjusted with the rotating torque $M_{B}$, the LTR value will decrease to 0.8 from 1 , and the roll angle speed will eventually return to 0 , which shows that the vehicle resumes a stable state.
4.3.2. Effects of Adjusting the Swing Bridge on the Roll Stability When Instability Occurs While Passing over Obstacles. Instability occurs when the vehicle crosses the triangle obstacle (with a base of $0.8 \mathrm{~m}$ and a height of $0.3 \mathrm{~m}$ ) at the forward speed of $7 \mathrm{~m} / \mathrm{s}$. Figure 11(b) shows the contrast of the motion states of the vehicle with and without adjusting the swing bridge when instability occurs during obstacle crossing. The LTR and the change in roll angular velocity show that adjusting the swing bridge can decrease the instability time of the vehicle and make the vehicle quickly recover from the unstable state to the steady state.

\section{Conclusion}

Wheel loaders, which are typical ASVs, are selected as the research objects in this study. A study on the control methods for active rollover protection of ASVs is conducted on the basis of an 8-DOF nonlinear dynamic model of ASVs. The established dynamic model is used to, respectively, study the effects of active braking, active steering, and adjusting the swing bridge on the roll stability of ASVs. The analysis results show the following:

(1) Active braking can improve the roll stability of ASVs during turning, and the inhibition effects on the instability that occurs while passing over obstacles are not obvious.

(2) Active steering can effectively improve the roll stability of ASVs while turning. When the vehicle rolls over around the positive direction of the $x$-axis in the process of obstacle crossing, active steering on the left can improve the roll stability of the vehicle, but active steering on the right can deteriorate the instability of the vehicle.

(3) Adjusting the swing bridge can change the posture and the position of the gravity center of the vehicle, thus improving the roll stability of ASVs. 

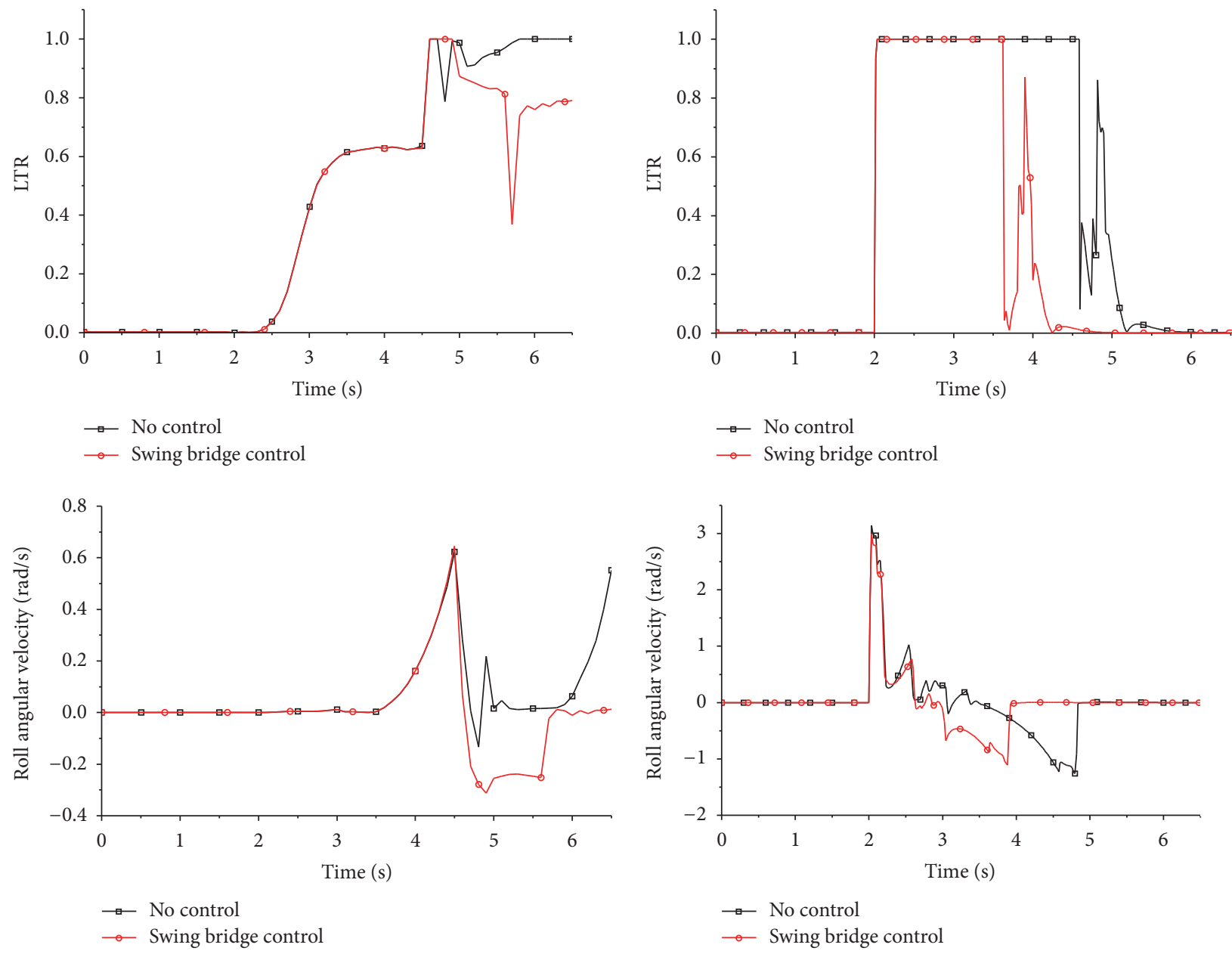

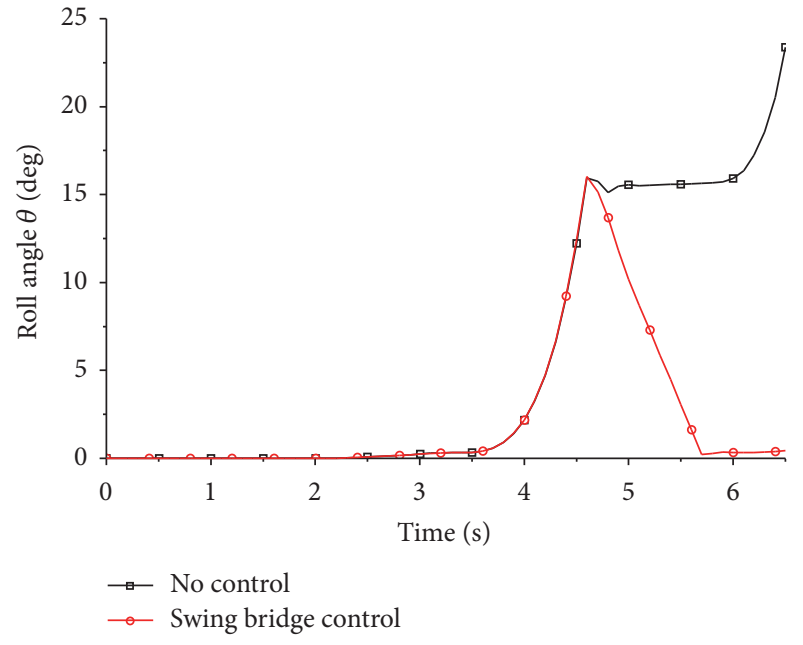

(a)

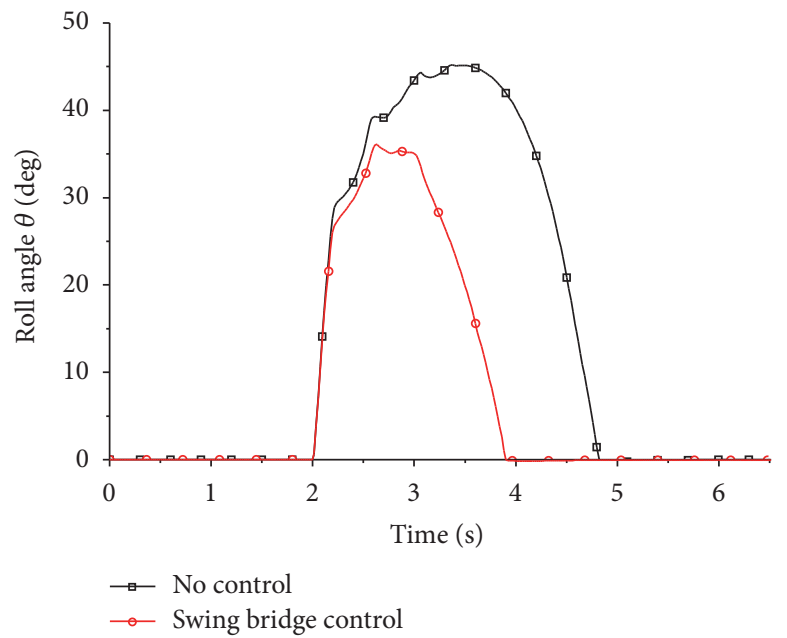

(b)

FIGURE 11: The motion states of the vehicle with and without adjusting the swing bridge. 


\section{Competing Interests}

The authors declare that there is no conflict of interests regarding the publication of this paper.

\section{Acknowledgments}

This study was supported by the National Natural Science Foundation of China (Grant no. 51505177), Science and Technology Development Program of Jilin Province (Grant no. 20160520073JH), and Postdoctoral Science Foundation of China (Grant no. 163808).

\section{References}

[1] N. L. Azad, Dynamic Modeling and Stability Controller Development for Articulated Steer Vehicles, University of Waterloo, Waterloo, Canada, 2006.

[2] ISO, "Earth-moving machinery-roll-over protective structures laboratory tests and performance requirements," ISO 3471: 2008, 2008

[3] R. C. Franklin, K.-L. Stark, and L. Fragar, "Intervention strategies for the retro-fitment of Rollover Protective Structures (ROPS) and fleet characteristic, farm tractors," Safety Science, vol. 44, no. 9, pp. 771-783, 2006.

[4] C. Chen, G. Wang, Y. Zhang, Y. Zhang, and J. Si, "Effect of lateral stiffness coefficient of loader ROPS on human injury in a lateral rollover incident," Biosystems Engineering, vol. 113, no. 2, pp. 207-219, 2012.

[5] S. Solmaz, M. Corless, and R. Shorten, "A methodology for the design of robust rollover prevention controllers for automotive vehicles with active steering," International Journal of Control, vol. 80, no. 11, pp. 1763-1779, 2007.

[6] C. Cheng and D. Cebon, "Improving roll stability of articulated heavy vehicles using active semi-trailer steering," Vehicle System Dynamics, vol. 46, no. 1, pp. 373-388, 2008.

[7] H. Imine, L. M. Fridman, and T. Madani, "Steering control for rollover avoidance of heavy vehicles," IEEE Transactions on Vehicular Technology, vol. 61, no. 8, pp. 3499-3509, 2012.

[8] B.-C. Chen and H. Peng, "Differential-braking-based rollover prevention for sport utility vehicles with human-in-the-loop evaluations," Vehicle System Dynamics, vol. 36, no. 4-5, pp. 359389, 2001.

[9] L. Chen and S. Hsu, "Investigation of driver-controller interaction in vehicle rollover prevention," in Proceedings of the IEEE International Conference on Systems, Man and Cybernetics (SMC '06), vol. 2, pp. 998-1003, Taipei, Taiwan, July 2007.

[10] J. Wang, D. A. Wilson, W. Xu, and D. A. Crolla, "Integrated vehicle ride and steady-state handling control via active suspensions," International Journal of Vehicle Design, vol. 42, no. 3-4, pp. 306-327, 2006.

[11] D. J. M. Sampson and D. Cebon, "Active roll control of single unit heavy road vehicles," Vehicle System Dynamics, vol. 40, no. 4, pp. 229-270, 2003.

[12] D. J. M. Sampson, G. McKevitt, and D. Cebon, "Development of an active roll control system for heavy vehicles," Vehicle System Dynamics, vol. 33, pp. 704-715, 2000.

[13] A. Y. Lee, "Coordinated control of steering and anti-roll bars to alter vehicle rollover tendencies," Journal of Dynamic Systems, Measurement and Control, Transactions of the ASME, vol. 124, no. 1, pp. 127-132, 2002.
[14] P. Gaspar, I. Szaszi, and J. Bokor, "Reconfigurable control structure to prevent the rollover of heavy vehicles," Control Engineering Practice, vol. 13, no. 6, pp. 699-711, 2005.

[15] D. Li, S. Du, and F. Yu, "Integrated vehicle chassis control based on direct yaw moment, active steering and active stabiliser," Vehicle System Dynamics, vol. 46, no. 1, pp. 341-351, 2008.

[16] S. Yim, "Design of a robust controller for rollover prevention with active suspension and differential braking," Journal of Mechanical Science and Technology, vol. 26, no. 1, pp. 213-222, 2012.

[17] H. B. Pacejka, Tire and Vehicle Dynamics, Society of Automotive Engineers, Warrendale, Pa, USA, 2002.

[18] X. Li, Y. Wu, W. Zhou, and Z. Yao, "Study on roll instability mechanism and stability index of articulated steering vehicles," Mathematical Problems in Engineering, vol. 2016, Article ID 7816503, 15 pages, 2016. 


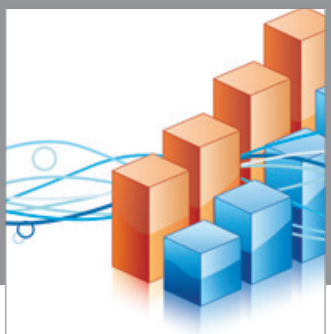

Advances in

Operations Research

vatem alat4

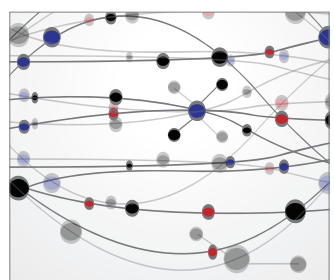

\section{The Scientific} World Journal
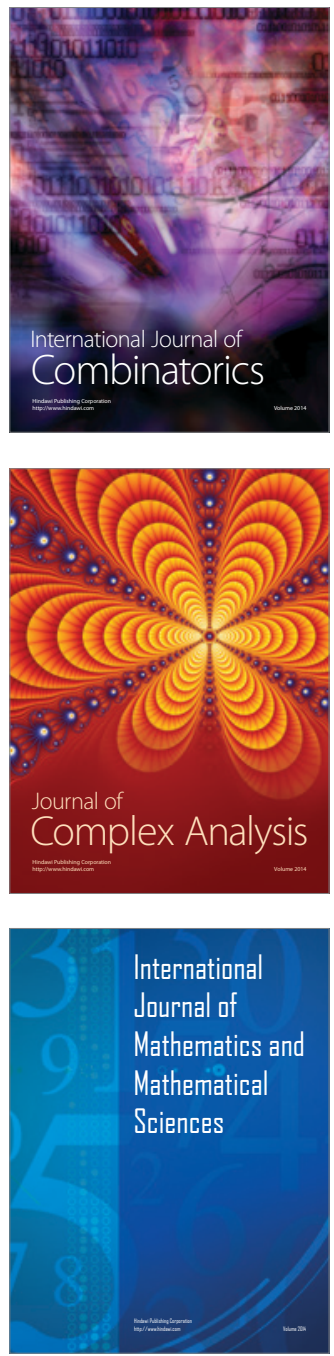
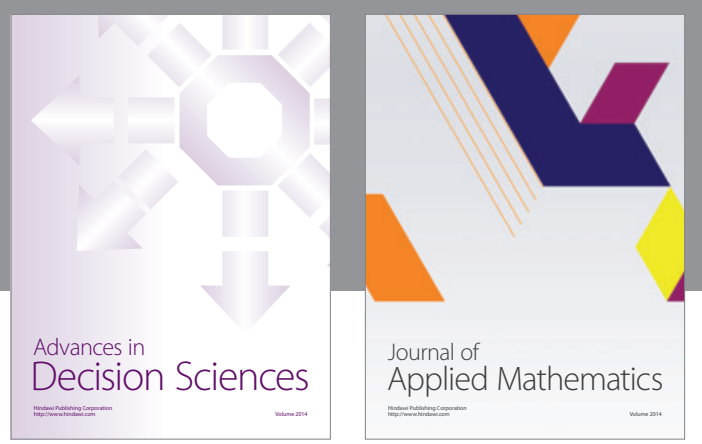

Algebra

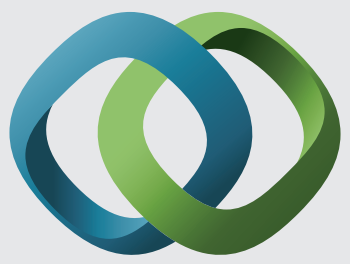

\section{Hindawi}

Submit your manuscripts at

http://www.hindawi.com
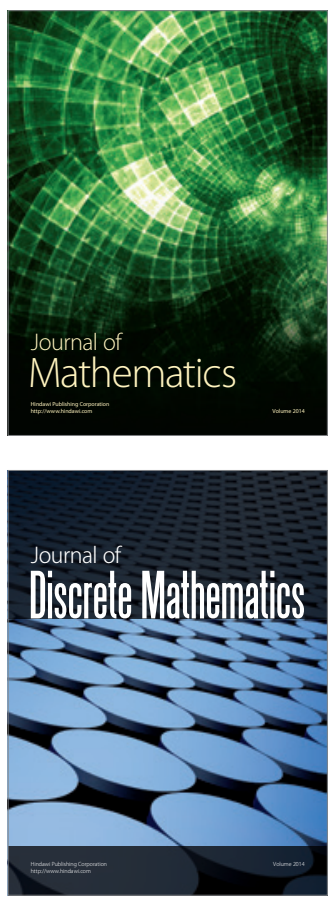

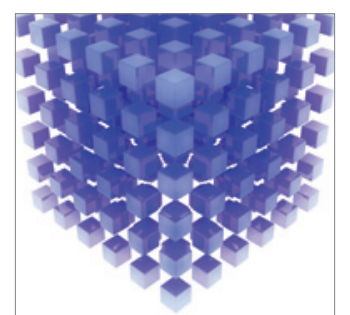

Mathematical Problems in Engineering
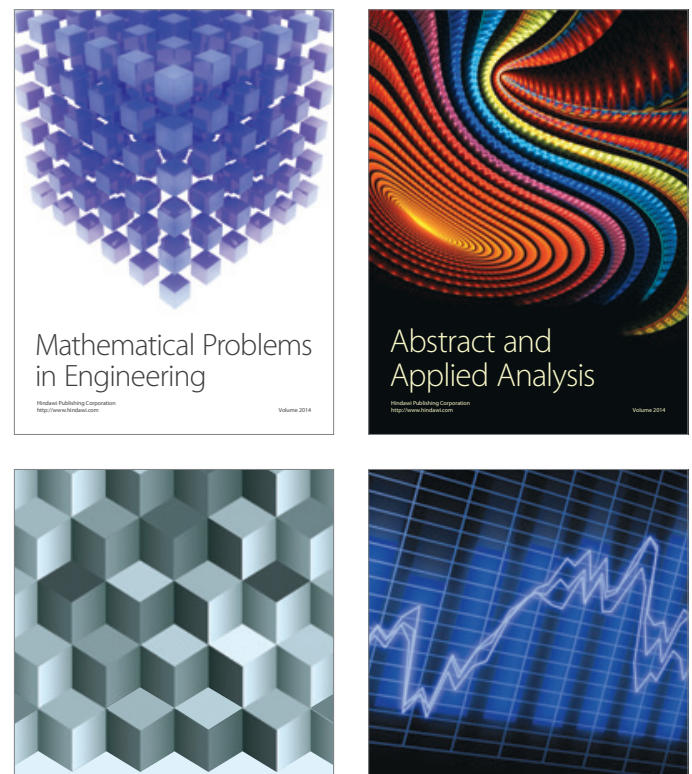

Journal of

Function Spaces

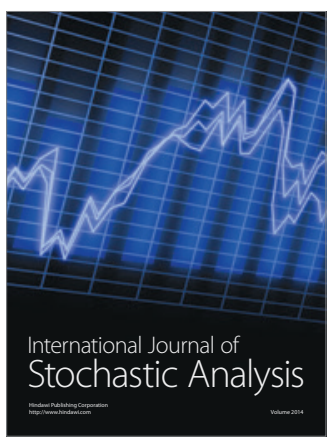

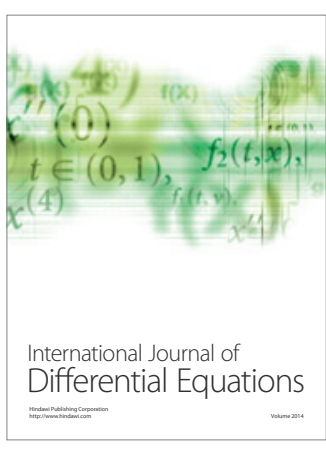
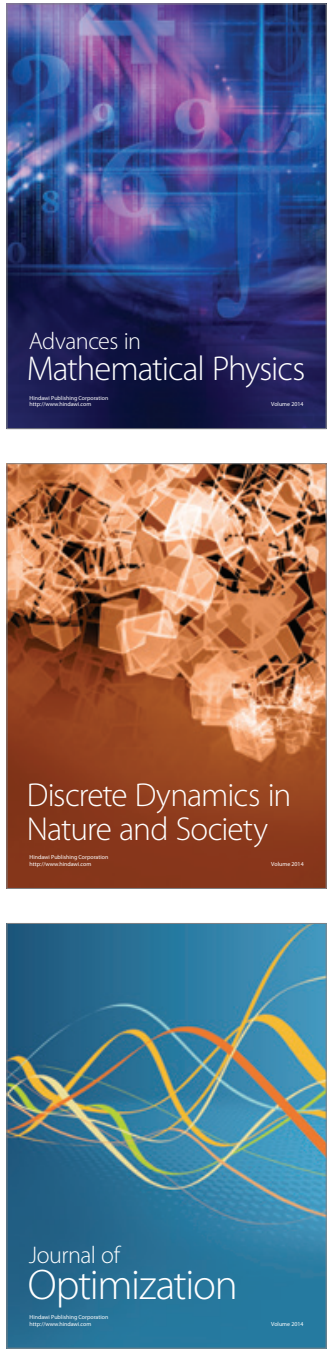